\title{
EFEITO DE PRÁTICAS CULTURAIS NA CONVERSÃO E NO BALANÇO ENERGÉTICOS $\left({ }^{1}\right)$
}

\author{
HENRIQUE PEREIRA DOS SANTOS $\left({ }^{2 *}\right)$; GILBERTO OMAR TOMM $\left({ }^{3}\right)$; \\ SILVIO TULIO SPERA $\left({ }^{3}\right)$; ALEXANDRE ÁVILA $\left({ }^{4}\right)$
}

\begin{abstract}
RESUMO
Desenvolveu-se de 1997 a 2003, em Passo Fundo (RS), um experimento constituído de quatro sistemas de manejo de solo (plantio direto, cultivo mínimo, preparo convencional de solo com arado de discos e preparo convencional de solo com arado de aivecas) e de três sistemas de rotação de culturas: sistema I (trigo/soja); sistema II (trigo/soja e ervilhaca/milho ou sorgo) e sistema III (trigo/soja, ervilhaca/ milho ou sorgo e aveia branca/soja). O delineamento experimental foi o de blocos ao acaso, com parcelas subdivididas e três repetições. A parcela principal foi constituída pelos sistemas de manejo de solo, e as subparcelas, pelos sistemas de rotação de culturas. Neste trabalho, apresentam-se a conversão energética (energia disponível/energia consumida) e o balanço energético (energia disponível - energia consumida) no período de 7 anos. No sistema plantio direto houve conversão e balanço energéticos (72,44 e 190.766 MJ ha ${ }^{-1}$ ) superiores ao cultivo mínimo (64,06 e $\left.167.349 \mathrm{MJ} \mathrm{ha}^{-1}\right)$, aos preparos convencionais de solo com arado de discos (54,35 e $\left.134.982 \mathrm{MJ} \mathrm{ha}^{-1}\right)$ e com arado de aivecas (52,02 e $\left.128.159 \mathrm{MJ}^{-1}\right)$ respectivamente. $\mathrm{O}$ trigo em rotação de culturas foi mais eficiente energeticamente do que a monocultura desse cereal. Na cultura de milho foi observada maior eficiência energética.
\end{abstract}

Palavras-chave: Conversão energética, balanço energético, rotação de culturas, preparo convencional de solo, cultivo mínimo, sistema plantio direto.

\section{ABSTRACT \\ EFFECT OF CULTURAL PRACTICES ON ENERGY CONVERSION AND BALANCE}

The effects of soil management systems and crop rotations were assessed from 1997 to 2003, in Passo Fundo, Rio Grande do Sul State, Brazil. Four soil management systems (no-tillage, minimum tillage, conventional tillage using disk plow, and conventional tillage using moldboard plow) and three crop rotation systems [system I (wheat/soybean), system II (wheat/soybean and common vetch/corn or sorghum), and system III (wheat/soybean, common vetch/corn or sorghum and white oats/soybean)] were compared. An experimental design of blocks at random with split-plots and three replications was used. The main plot consisted of soil management systems, while the split-plots consisted of crop rotation systems. Energy conversion (energy available/energy consumed) and balance (energy available - energy consumed) during a seven-year period is presented in this paper. No-tillage showed higher energy conversion and balance (72.44 and 190,766 $\mathrm{MJ} \mathrm{ha}^{-1}$ ) than minimum tillage (64.06 and 167,349 $\left.\mathrm{MJ} \mathrm{ha}^{-1}\right)$, conventional tillage using disk plow ( 54.35 and $134,982 \mathrm{MJ} \mathrm{ha}^{-1}$ ), and conventional tillage using moldboard (52.02 and 128,159 $\mathrm{MJ} \mathrm{ha}^{-1}$ ), respectively. Wheat within crop rotations presented higher energy efficiency in energy than the monoculture of this cereal. The corn crop was observed the highest energy efficiency of this study.

Key words: energy conversion, energy balance, crop rotation, conventional tillage, minimum tillage, no-tillage.

$\left({ }^{1}\right)$ Recebido para publicação em 26 de setembro de 2005 e aceito em 15 de dezembro de 2006.

$\left({ }^{2}\right)$ Embrapa Trigo, Caixa Postal 451, 99001-970 Passo Fundo (RS) Brasil. Com bolsa de produtividade em pesquisa do CNPq-PQ. E-mail: hpsantos@cnpt.embrapa.br $\left(^{*}\right)$ Autor correspondente.

$\left({ }^{3}\right)$ Embrapa Trigo. E-mail: tomm@cnpt.embrapa.br; spera@cnpt.embrapa.br

$\left({ }^{4}\right)$ Acadêmico de Agronomia da UPF/FAMV. Tomaz Gonzaga 461, 99020-170 Passo Fundo (RS) Brasil. Com bolsa de iniciação científica do CNPq. 


\section{INTRODUÇÃO}

O balanço energético constitui importante instrumento para tomada de decisões relativas à adoção de novas técnicas e manejos agropecuários, com potencial para economizar energia e aumentar a eficiência dos insumos, reduzindo custos em sistemas de produção, que apresentam uso intensivo energético em suas várias formas (CAMPOS e CAMPOS, 2004). Assim, a geração de informações específicas para espécies em sistemas de manejo de solo ou rotação de culturas torna-se de grande valor.

Análise energética de agrossistemas tem por objetivo descrever os fluxos de energia e seu funcionamento e determinar o grau de eficiência energética a partir de medidas parciais, relacionadas apenas, como terra, trabalho ou capital (DE MoRI, 1998). A análise de fluxo energético requer a unificação do produto de diferentes fontes e conversores de energia, como máquinas, trabalho humano e combustível, em uma mesma unidade calórica (COMITRE, 1995).

Assim, define-se balanço de energia como atividade ou instrumento destinado a contabilizar a energia disponível e a energia consumida em determinado sistema de produção. Seu objetivo principal é traduzir em unidades ou equivalentes energéticos os fatores de produção e os intermediários, possibilitando a construção de indicadores comparáveis entre si, que permitam a intervenção no sistema produtivo visando melhorar a eficiência (BUENO et al., 2000). Todavia, nem toda tecnologia usada em propriedades apresenta eficiência energética. Estudos realizados por QUESADA et al. (1987) e por ZENTNER et al. (1984), permitiram identificar espécies que tiveram balanço energético negativo.

Poucos são os trabalhos existentes no Brasil sobre conversão e balanço energético em que se comparam espécies e cultivos sob diferentes sistemas de manejo de solo e de rotação de culturas. Diversos autores estudaram espécies isoladamente (QUESADA et al., 1987; Quesada e Beber, 1990; Monegat, 1998). São poucos os trabalhos relativos à conversão e ao balanço energético de sistemas de rotação de culturas ou sistemas mistos (lavoura + pecuária) (SANTOS et al., 2000, 2001).

SANTOS et al. (2000), em sistemas mistos sob plantio direto, verificaram diferenças significativas entre os sistemas de produção de grãos para os índices de conversão e de balanço energético. Segundo esses autores, os sistemas II (trigo/soja e pastagem de aveia preta + ervilhaca/milho) e III (trigo/soja, pastagem de aveia preta + ervilhaca/soja e pastagem de aveia preta + ervilhaca/milho) foram mais eficientes energeticamente que os sistemas I (trigo/soja, pastagem de aveia preta/soja e pastagem de aveia preta/soja) e IV (trigo/soja, aveia branca/soja e aveia branca/soja). Contudo, SANTOS et al. (2001) não observaram diferenças significativas para conversão e balanço energético entre os sistemas estudados.

Dentre os estudos, verificou-se a existência de pouca literatura sobre manejo de solo sob o ponto de vista de consumo de energia (Rego, 1993; Hernánz et al., 1995; Borin et al., 1997; Monegat, 1998).

Este trabalho teve como objetivo avaliar o efeito de práticas culturais na conversão energética e no balanço energético.

\section{MATERIAL E MÉTODOS}

Dados de rendimento de grãos obtidos no experimento de sistemas de manejo de solo e de rotação de culturas envolvendo a cultura de trigo, instalado na Embrapa Trigo, no município de Passo Fundo (RS), de 1997 a 2003, em solo classificado como Latossolo Vermelho Distrófico típico serviram de base para este trabalho.

Os tratamentos consistiram de quatro sistemas de manejo de solo: 1) plantio direto; 2) preparo de solo com implemento para cultivo mínimo marca Jan, no inverno, e semeadura direta, no verão; 3) preparo convencional de solo com arado de discos, no inverno, e semeadura direta, no verão, e 4) preparo convencional de solo com arado de aivecas, no inverno, e semeadura direta, no verão e três sistemas de rotação de culturas: sistema I (trigo/soja em monocultura), sistema II (trigo/soja e ervilhaca/milho ou sorgo) e sistema III (trigo/soja, ervilhaca/milho ou sorgo e aveia branca/soja).

O delineamento experimental foi o de blocos ao acaso, com parcelas subdivididas e três repetições. A parcela principal $(4 \mathrm{~m}$ de largura por $90 \mathrm{~m}$ de comprimento) foi constituída pelos sistemas de manejo de solo e as subparcelas ( $4 \mathrm{~m}$ de largura por $10 \mathrm{~m}$ de comprimento), pelas culturas componentes das rotações de culturas.

As amostragens de solo, para determinação dos níveis de nutrientes e do conteúdo de matéria orgânica, foram realizadas em todas as parcelas, após a colheita das culturas de inverno e de verão.

Realizaram-se a semeadura, o controle de plantas daninhas e os tratamentos fitossanitários para cada cultura, conforme a recomendação. A colheita das culturas produtoras de grãos foi efetuada com colhedeira especial para parcelas experimentais. $\mathrm{O}$ rendimento de grãos de aveia branca, milho, soja e trigo foi corrigido para umidade de $13 \%$. 
$\mathrm{Na}$ quantificação dos dados obtidos das culturas utilizaram-se as matrizes de produção, a partir das quais se procederam as transformações para contabilizar a energia disponível e consumida nesses processos. Para os cálculos dos diversos índices envolvendo sistemas, rendimento de grãos, quantidade de palha remanescente, quantidade de $\mathrm{N}$ na matéria seca e operações de campo, foram empregados dados e orientações gerados por Pimentel (1980), ZENTner et al. (1984), Embrapa (1991), Freitas et al. (1994), Marchioro (1985), Monegat (1998) e Santos et al. (2001). No caso da ervilhaca, de 1997 a 2003, considerou-se como rendimento a contribuição auferida com base no percentual de nitrogênio da matéria seca (Tabela 1). Os dados foram transformados em MJ (kcal x 1.000 x 4,186 J).

Tabela 1. Coeficientes energéticos por hectare dos insumos, das operações de campo, do rendimento de grãos e da matéria seca utilizados nos sistemas de manejo de solo e de rotação de culturas, em 2003. Passo Fundo (RS)

\begin{tabular}{|c|c|c|c|}
\hline Especificação & Unidade & $\mathrm{J}$ (joule) & Referência \\
\hline & & unidade & \\
\hline \multicolumn{4}{|l|}{ Energia consumida: } \\
\hline Semente - aveia branca & $\mathrm{kg}$ & 17.196 & Pimentel (1980) \\
\hline - ervilhaca & $\mathrm{kg}$ & 31.747 & Pimentel (1980) \\
\hline - milho & $\mathrm{kg}$ & 103.838 & Pimentel (1980) \\
\hline - soja & $\mathrm{kg}$ & 31.747 & Pimentel (1980) \\
\hline - sorgo & $\mathrm{kg}$ & 59.524 & Pimentel (1980) \\
\hline - trigo & $\mathrm{kg}$ & 12.566 & Pimentel (1980) \\
\hline Fertilizante - N & $\mathrm{kg}$ & 77.516 & Marchioro (1985) \\
\hline$-P$ & $\mathrm{~kg}$ & 14.023 & Marchioro (1985) \\
\hline$-K$ & $\mathrm{~kg}$ & 9.691 & Marchioro (1985) \\
\hline Fungicida - epoxiconazole & $\mathrm{L}$ & 271.713 & Santos et al. (2001) \\
\hline - metconazole & $\mathrm{L}$ & 271.713 & Pimentel (1980) \\
\hline - propoconazole & $\mathrm{L}$ & 271.713 & Pimentel (1980) \\
\hline - triadimenol & $\mathrm{L}$ & 271.713 & Pimentel (1980) \\
\hline Herbicida - atrazina & $\mathrm{L}$ & 418.223 & Pimentel (1980) \\
\hline - atrazina + simazina & $\mathrm{L}$ & 418.223 & Pimentel (1980) \\
\hline - bentazon & $\mathrm{L}$ & 418.223 & Pimentel (1980) \\
\hline - diclofob-metil & $\mathrm{L}$ & 418.223 & Pimentel (1980) \\
\hline - glifosato & $\mathrm{L}$ & 418.223 & Pimentel (1980) \\
\hline - imazaquin & $\mathrm{L}$ & 418.223 & Santos et al. (2001) \\
\hline - metdulfuron-metil & $\mathrm{L}$ & 418.223 & Santos et al. (2001) \\
\hline - Sethoxydim & $\mathrm{L}$ & 418.223 & Santos et al. (2001) \\
\hline - sulfentrazone & $\mathrm{L}$ & 418.223 & Santos et al. (2001) \\
\hline - trifluralin & $\mathrm{L}$ & 418.223 & Pimentel (1980) \\
\hline Inseticida - clorpirifós & $\mathrm{kg}$ & 311.020 & Pimentel (1980) \\
\hline - deltametrina & $\mathrm{L}$ & 363.805 & Pimentel (1980) \\
\hline - formicida & $\mathrm{kg}$ & 311.020 & Pimentel (1980) \\
\hline - imidaclopride & $\mathrm{kg}$ & 311.020 & Pimentel (1980) \\
\hline - lambdacilotrina & $\mathrm{L}$ & 363.805 & Pimentel (1980) \\
\hline - monocrotofós & $\mathrm{L}$ & 363.805 & Pimentel (1980) \\
\hline Semeadura e adubação & h/e.t. & 29.277 & Pimentel (1980) \\
\hline Aplicação de cobertura ou produto & h/e.t. & 9.862 & Pimentel (1980) \\
\hline Colheita mecânica & $\mathrm{h} / \mathrm{cal}$. & 783.330 & Pimentel (1980) \\
\hline \multicolumn{4}{|l|}{ Energia disponível: } \\
\hline - aveia branca & $\mathrm{kg}$ & 15.631 & Embrapa (1991) \\
\hline - ervilhaca & $\mathrm{kg}$ & 9.707 & Freitas et al. (1994) \\
\hline - milho & $\mathrm{kg}$ & 15.111 & Marchioro (1985) \\
\hline - soja & $\mathrm{kg}$ & 16.744 & Marchioro (1985) \\
\hline - sorgo & $\mathrm{kg}$ & 16.514 & Marchioro (1985) \\
\hline - trigo & $\mathrm{kg}$ & 15.451 & Marchioro (1985) \\
\hline
\end{tabular}

h/e.t.: hora de trabalho com equipamento e trator; h/cal.: hora de trabalho com colhedeira. 
Como energia disponível ou receita energética $\left(\mathrm{MJ} \mathrm{ha}{ }^{-1}\right)$, considerou-se a transformação em energia do rendimento de grãos, da quantidade de $\mathrm{N}$ na matéria seca e da quantidade de palha remanescente das espécies. Como energia consumida $\left(\mathrm{MJ} \mathrm{ha}{ }^{-1}\right)$, estimou-se a soma dos coeficientes energéticos correspondentes aos corretivos, fertilizantes, sementes, fungicidas, herbicidas e inseticidas usados em cada sistema, bem como a energia consumida pelas operações (manejo de solo, semeadura, adubação, aplicação de defensivos e colheita). A conversão energética resulta da divisão da energia disponível $\left(\mathrm{MJ} \mathrm{ha}{ }^{-1}\right.$ ) pela consumida $\left(\mathrm{MJ} \mathrm{ha}^{-1}\right)$, em cada sistema ou rotação. $\mathrm{O}$ balanço energético resulta da diferença entre a energia disponível $\left(\mathrm{MJ} \mathrm{ha}^{-1}\right)$ e a consumida (MJ $\left.\mathrm{ha}^{-1}\right)$, em cada sistema ou rotação.

A análise estatística consistiu na análise da variância de conversão energética e balanço energético, dentro de cada ano (inverno + verão) e na média conjunta dos anos, nos períodos de 1997 a 2003. Na análise da variância, consideraram-se as energias disponível e consumida pelas culturas que compõem os sistemas de manejo do solo e de rotação de culturas estudados. Nas análises conjuntas, consideraram-se os tratamentos como efeito fixo, e o efeito do ano, como aleatório. Em razão do número balanceado de parcelas nos sistemas de manejo de solo, as diferenças entre as médias de tratamentos foram avaliadas pelo teste de Duncan, ao nível de 5 $\%$. Em face do número de parcelas diversas por rotação de culturas, a avaliação, em todas as análises, foi realizada pelo teste $F$, usando-se contrastes que incluem os diferentes tratamentos dos sistemas envolvidos em cada comparação (STATISTICAL, 2003). O método de contrastes compara os sistemas dois a dois, em uma unidade de base homogênea.

\section{RESULTADOS E DISCUSSÃO}

Ao se compararem as médias de 1997/98 a 2003/04, observaram-se diferenças significativas entre os sistemas de manejo de solo para conversão energética em todas as safras estudadas e na média conjunta das safras (Tabela 2). Nas safras de 1997/ 98, 1998/99, 1999/00, 2000/01 e 2002/03, o sistema plantio direto foi de maior valor de conversão energética do que os demais sistemas de manejo de solo. Hetz e Melo (1997) relatam que o acréscimo no rendimento das culturas (milho e trigo) e, conseqüentemente, da eficiência energética do sistema plantio direto aumentam com o passar do tempo. $\mathrm{Na}$ safra de $2001 / 2002$, no sistema plantio direto, cultivo mínimo e no preparo convencional de solo com arado de discos, observaram-se valores mais elevados para a conversão energética. Entretanto, o preparo convencional de solo com arado de discos foi semelhante estatisticamente ao preparo com arado de aivecas. Na safra de 2003/2004, o cultivo mínimo, o preparo convencional de solo com arado de aivecas e com arado de discos proporcionaram índices mais elevados de conversão energética. Contudo, o preparo convencional de solo com arado de aivecas foi estatisticamente equivalente ao plantio direto.

Tabela 2. Efeito de sistemas de manejo de solo na conversão energética nas safras (inverno + verão) de $1997 / 98$ a 2003/04. Passo Fundo (RS)

\begin{tabular}{|c|c|c|c|c|c|}
\hline \multirow{3}{*}{ Safra } & \multicolumn{4}{|c|}{ Conversão energética (MJ ha-1) } & \multirow{3}{*}{ Média } \\
\hline & \multicolumn{4}{|c|}{ Tipo de manejo de solo (inverno + verão) } & \\
\hline & PD & PCD & PCA & PM & \\
\hline $1997 / 98$ & $75,26 \mathrm{~A}$ & $51,49 B C$ & $44,46 \mathrm{C}$ & $60,36 \mathrm{~B}$ & 57,89 \\
\hline 1998/99 & $68,91 \mathrm{~A}$ & $40,86 \mathrm{C}$ & $39,31 \mathrm{C}$ & $58,19 B$ & 51,82 \\
\hline $1999 / 00$ & $87,86 \mathrm{~A}$ & $53,83 \mathrm{C}$ & $53,20 \mathrm{C}$ & $74,46 \mathrm{~B}$ & 67,34 \\
\hline $2000 / 01$ & $91,97 \mathrm{~A}$ & $59,11 C$ & $57,35 \mathrm{C}$ & $78,57 \mathrm{~B}$ & 71,75 \\
\hline $2001 / 02$ & $63,84 \mathrm{~A}$ & $61,32 \mathrm{AB}$ & $58,31 \mathrm{~B}$ & $62,33 \mathrm{~A}$ & 61,45 \\
\hline $2002 / 03$ & $83,93 \mathrm{~A}$ & $76,27 \mathrm{~B}$ & $73,30 \mathrm{~B}$ & $76,52 \mathrm{~B}$ & 77,51 \\
\hline $2003 / 04$ & $35,29 B$ & $37,55 \mathrm{AB}$ & $38,18 \mathrm{~A}$ & $38,01 \mathrm{~A}$ & 37,26 \\
\hline Média & $72,44 \mathrm{~A}$ & $54,35 \mathrm{C}$ & $52,02 \mathrm{C}$ & $64,06 \mathrm{~B}$ & 60,72 \\
\hline
\end{tabular}

PD: plantio direto; PCD: preparo convencional de solo com arado de discos, no inverno, e semeadura direta, no verão; PCA: preparo convencional de solo com arado de aivecas, no inverno, e semeadura direta, no verão; e PM: cultivo mínimo, no inverno, e semeadura direta, no verão. Médias seguidas da mesma letra, na horizontal, não apresentam diferenças significativas, pelo teste de Duncan a $5 \%$. 
Na média conjunta das safras $(1997 / 98$ a 2003/04), no plantio direto observou-se conversão energética superior à do cultivo mínimo e à do preparo convencional de solo com arado de discos e com arado de aivecas. Mesquita et al. (1982), trabalhando com três sistemas de manejo de solo para a cultura de soja, observaram que o sistema mais eficiente em consumo de energia foi o de plantio direto, em relação aos demais sistemas. Conforme Hetz e Barrios (1987), os custos energéticos dos sistemas de manejo de solo com cultivo mínimo e plantio direto foram notadamente menores do que com preparo convencional de solo com arado de discos.

Na avaliação dos primeiros dez anos (1986 a 1995) desse mesmo trabalho, realizada por SANTOS et al. (2003), o sistema plantio direto não diferiu estatisticamente do cultivo mínimo para os índices de conversão de energia, mas foi superior aos preparos convencionais de solo com arado de discos e de aivecas. A maior conversão energética no sistema plantio direto, em relação aos sistemas de preparo convencionais de solo, pode ser explicada, em parte, pela redução das demandas energéticas propiciadas pela diminuição no número de operações agrícolas (ZENTNER et al., 1991; BURT et al., 1994; HERNÁNZ et al., 1995; BorIN et al., 1997). Ademais, deve-se considerar que, em todos os sistemas de manejo de solo deste estudo, foi computada, também, a palhada remanescente como energia disponível, que no plantio direto foi mais elevada que nos demais sistemas estudados.

$\mathrm{Na}$ maioria das safras estudadas e na análise da média do conjunto dos anos, houve diferenças significativas entre a conversão energética dos diferentes sistemas de rotação de culturas (Tabela 3). $\mathrm{O}$ valor mais elevado, na maioria das safras, no tocante à conversão energética, manifestou-se sob rotação de culturas, nos sistemas II (trigo/soja e ervilhaca/milho ou sorgo) e III (trigo/soja, ervilhaca/ milho ou sorgo e aveia branca/soja), do que no sistema I (trigo/soja), com monocultura de inverno e de verão. De acordo com Pellizzi (1992), o cultivo de cereais em monocultura tende a consumir de $1 \%$ a $3 \%$ mais energia do que em rotação de culturas devido à necessidade de controle de doenças.

Na análise da média conjunta das safras, os sistemas II e III foram superiores ao sistema I para o índice de conversão energética (Tabela 2). Esse fato se deve, em parte, às culturas de milho e de sorgo que tiveram maior conversão energética do que a de soja e as demais espécies de inverno estudadas. HeTz e Melo (1997), relatam a eficiência do milho (127.218 $\mathrm{MJ} \mathrm{ha}^{-1}$ ) em converter energia, em comparação com o trigo (63.250 $\mathrm{MJ} \mathrm{ha}^{-1}$ ). Santos e Reis (1995), trabalhando com sistemas de rotação de culturas, no Estado do Paraná, observaram também maior eficiência energética do milho, em relação à soja e às demais espécies de inverno. Neste estudo, o milho produziu mais palha do que o trigo. Portanto, a rotação de culturas (sistemas II e III) foi mais eficiente na conversão de energia, em relação à monocultura trigo/soja (sistema I). Essa eficiência dos sistemas de rotação de culturas pode ser explicada, em parte, pela quantidade de palha remanescente do milho e do sorgo, adicionada como energia disponível que neste estudo foi maior que as culturas de inverno e a da soja.

Tabela 3. Efeito de sistemas de rotação de culturas na conversão energética nas safras (inverno + verão) de $1997 / 98$ a 2003/04. Passo Fundo (RS)

\begin{tabular}{|c|c|c|c|c|c|c|}
\hline \multirow{3}{*}{ Safra } & \multicolumn{6}{|c|}{ Conversão energética (MJ ha ${ }^{-1}$ ) } \\
\hline & \multicolumn{6}{|c|}{ Sistema de rotação de culturas (inverno + verão) $\left({ }^{1}\right)$} \\
\hline & Sistema I & Sistema II & Sistema III & I $\times$ II & I x III & II $x$ III \\
\hline & & & & \multicolumn{3}{|c|}{ Contraste entre sistemas $(\mathrm{P}>\mathrm{F})$} \\
\hline $1997 / 98$ & 51,99 & 59,99 & 58,44 & ns & ns & ns \\
\hline 1998/99 & 33,74 & 56,55 & 54,71 & $* *$ & ** & ns \\
\hline $1999 / 00$ & 49,81 & 72,33 & 69,86 & ** & ** & ns \\
\hline $2000 / 01$ & 54,08 & 74,93 & 75,52 & $* *$ & $* *$ & ns \\
\hline $2001 / 02$ & 40,73 & 69,61 & 62,92 & $* *$ & $* *$ & $* *$ \\
\hline $2002 / 03$ & 51,78 & 88,58 & 78,70 & $* *$ & $* *$ & $* *$ \\
\hline $2003 / 04$ & 22,73 & 44,37 & 37,38 & $* *$ & $* *$ & $* *$ \\
\hline Média & 43,55 & 66,62 & 62,50 & $* *$ & $* *$ & $\mathrm{~ns}$ \\
\hline
\end{tabular}

$\left({ }^{1}\right)$ Sistema I: trigo/soja; Sistema II: trigo/soja e ervilhaca/milho ou sorgo; e Sistema III: trigo/soja, aveia branca/soja e ervilhaca/milho ou sorgo. ns: não significativo; **: nível de significância de $1 \%$ (teste $\mathrm{F}$ para constrastes). 
ZENTNER et al. (1984), trabalhando durante 12 anos, observaram maiores índices de conversão energética (MJ ha-1) nos sistemas de rotação com um ano e dois anos sem trigo - 3,89 e 4,06 respectivamente - que sua monocultura desse cereal $(2,85)$. Porém, no Canadá apenas é possível uma cultura por ano; por esse motivo, a conversão energética foi bem inferior aos verificados neste estudo.

SANTOS et al. (2000), trabalhando com sistemas mistos, de lavoura e pecuária, durante seis anos, sob sistema de plantio direto, verificaram que os sistemas I (trigo/soja e pastagem de aveia preta + ervilhaca/ milho - 24,20) e II (trigo/soja, pastagem de aveia preta + ervilhaca/soja e pastagem de aveia preta + ervilhaca/milho - 22,77) tiveram maiores índices de conversão energética $\left(\mathrm{MJ} \mathrm{ha}^{-1}\right)$ do que os sistemas III (trigo/soja, pastagem de aveia preta / soja e pastagem de aveia preta/milho - 15,86) e IV (trigo/soja, aveia branca/soja e aveia branca/soja - 18,13). De acordo com esses autores, o milho foi a espécie com maior conversão energética, daí a importância dessa gramínea em sistemas de rotação de culturas. SANTOS et al. (2001), avaliaram a conversão energética de sete sistemas de rotação de culturas, durante nove anos, verificando que esses sistemas, na maioria das safras, foram energeticamente mais eficientes do que a monocultura trigo/soja ou pousio/soja.

Neste trabalho, observaram-se nos sistemas de manejo de solo e de rotação de culturas avaliados índices de conversão energética positivos, revelando que todos produziram mais energia do que consumiram. Nesse caso, os sistemas avaliados podem ser considerados sustentáveis do ponto de vista energético.

Nas médias, comparando o balanço energético de 1997/98 a 2003/04, houve diferenças significativas entre os sistemas de rotação de culturas em todas as safras estudadas e na média conjunta das safras (Tabela 4). Nas safras de 1997/98, 1998/99, 1999/00, 2000/01 e 2002/03, o balanço energético do sistema plantio direto foi superior aos demais sistemas de manejo de solo. Na safra de 2001/02, o plantio direto e o cultivo mínimo tiveram os melhores balanços energéticos. Entretanto, o cultivo mínimo foi semelhante estatisticamente ao preparo convencional de solo com arado de discos. Por sua vez, nessa safra, o preparo convencional de solo com arado de aivecas apresentou o menor valor. Na safra de 2003/2004, o cultivo mínimo e o preparo convencional de solo com arado de discos e com arado de aivecas revelaram os maiores balanços energéticos. Todavia, esses dois últimos sistemas se equivalem estatisticamente com o sistema plantio direto.

Na média conjunta das safras (1997/98 a 2003/04), o plantio direto foi superior aos demais sistemas de manejo de solo para os índices de balanço energético (Tabela 4). O cultivo mínimo situou-se em posição intermediária para o índice de balanço energético, enquanto o preparo convencional de solo com arado de discos e de com arado de aivecas, os menores. Neste estudo, o sistema de manejo de solo que mais consumiu energia (preparo convencional de solo com arado de aivecas) obteve menor retorno energético.

Tabela 4. Efeito de sistemas de manejo de solo no balanço energético nas safras (inverno + verão) de 1997/98 a 2003/ 04. Passo Fundo (RS)

\begin{tabular}{lccccc}
\hline \multirow{2}{*}{ Safra } & \multicolumn{5}{c}{ Balanço energético (MJ ha ${ }^{-1}$ ) } \\
\cline { 2 - 5 } & \multicolumn{4}{c}{ Tipo de manejo de solo (inverno + verão) } & \multirow{2}{*}{ Média } \\
\cline { 2 - 5 } $1997 / 98$ & $200.497 \mathrm{~A}$ & $139.193 \mathrm{BC}$ & $113.487 \mathrm{C}$ & $160.269 \mathrm{~B}$ & 153.362 \\
$1998 / 99$ & $199.132 \mathrm{~A}$ & $108.342 \mathrm{C}$ & $103.114 \mathrm{C}$ & $165.979 \mathrm{~B}$ & 144.141 \\
$1999 / 00$ & $249.661 \mathrm{~A}$ & $141.416 \mathrm{C}$ & $140.528 \mathrm{C}$ & $211.108 \mathrm{~B}$ & 185.678 \\
$2000 / 01$ & $240.699 \mathrm{~A}$ & $146.477 \mathrm{C}$ & $141.432 \mathrm{C}$ & $202.561 \mathrm{~B}$ & 182.792 \\
$2001 / 02$ & $145.397 \mathrm{~A}$ & $134.576 \mathrm{BC}$ & $128.791 \mathrm{C}$ & $142.429 \mathrm{AB}$ & 137.799 \\
$2002 / 03$ & $214.985 \mathrm{~A}$ & $187.830 \mathrm{BC}$ & $181.317 \mathrm{C}$ & $198.161 \mathrm{~B}$ & 195.574 \\
$2003 / 04$ & $84.988 \mathrm{~B}$ & $87.044 \mathrm{AB}$ & $88.446 \mathrm{AB}$ & $90.937 \mathrm{~A}$ & 87.856 \\
\hline Média & $190.766 \mathrm{~A}$ & $134.982 \mathrm{C}$ & $128.159 \mathrm{C}$ & $167.349 \mathrm{~B}$ & 155.314 \\
\hline
\end{tabular}

PD: plantio direto; PCD: preparo convencional de solo com arado de discos, no inverno, e semeadura direta, no verão; PCA: preparo convencional de solo com arado de aivecas, no inverno, e semeadura direta, no verão; e PM: cultivo mínimo, no inverno, e semeadura direta, no verão. Médias seguidas da mesma letra, na horizontal, não apresentam diferenças significativas, pelo teste de Duncan a $5 \%$. 
Na avaliação dos primeiros dez anos (1986 a 1995) desse mesmo trabalho, realizada por SANTOS et al. (2003), o balanço energético no sistema plantio direto não diferiu estatisticamente do cultivo mínimo, mas foi superior aos preparos convencionais de solo com arado de discos e com arado de aivecas.

Em todas as safras estudadas e na média conjunta das safras, comparadas duas a duas, houve diferenças significativas entre o balanço energético obtido nos diferentes sistemas de rotação de culturas avaliados (Tabela 5). Na média conjunta das safras (de 1997/98 a 2003/2004), para o índice de balanço energético, os sistemas II e III foram estatisticamente semelhantes entre si, e superiores ao sistema I (Tabela 5). Isso se deve, em parte, à cultura de milho ou de sorgo que foi a espécie mais eficiente no aproveitamento da energia disponível.

Tabela 5. Efeito de sistemas de rotação de culturas no balanço energético nas safras (inverno + verão) de $1997 / 98$ a 2003/04. Passo Fundo (RS)

\begin{tabular}{|c|c|c|c|c|c|c|}
\hline \multirow{3}{*}{ Safra } & \multicolumn{6}{|c|}{ Balanço energético $\left(\mathrm{MJ} \mathrm{ha}^{-1}\right)$} \\
\hline & \multicolumn{6}{|c|}{ Sistema de rotação de culturas (inverno + verão) } \\
\hline & Sistema I & Sistema II & Sistema III & $\mathrm{I} \times \mathrm{II}$ & $\mathrm{I} \times \mathrm{III}$ & II $x$ III \\
\hline & & & & \multicolumn{3}{|c|}{ Contraste entre sistema $\mathrm{s}(\mathrm{P}>\mathrm{F})$} \\
\hline $1997 / 98$ & 171.212 & 145.321 & 152.772 & ns & ns & ns \\
\hline 1998/99 & 106.140 & 148.192 & 154.108 & * & ** & ns \\
\hline $1999 / 00$ & 170.751 & 179.383 & 194.854 & ns & ns & ns \\
\hline $2000 / 01$ & 149.382 & 176.649 & 198.027 & ns & $* *$ & ns \\
\hline $2001 / 02$ & 113.210 & 137.841 & 145.970 & $* *$ & $* *$ & $*$ \\
\hline $2002 / 03$ & 172.626 & 200.723 & 199.848 & $* *$ & $*$ & ns \\
\hline $2003 / 04$ & 70.404 & 95.713 & 88.433 & ** & ** & ** \\
\hline Média & 136.246 & 154.832 & 162.002 & * & ** & ns \\
\hline
\end{tabular}

Sistema I: trigo/soja. Sistema II: trigo/soja e ervilhaca/milho ou sorgo. Sistema III: trigo/soja, aveia branca/soja e ervilhaca/milho ou sorgo. ns: não significativo; *: nível de signif,icância de 5\% (teste F para constrastes); **: nível de significância de 1\% (teste F para constrastes).

Em SAntos et al. (2000), nota-se que nos sistemas mistos, os maiores índices de balanço energético dos sistemas II e III decorrem da cultura de milho, que aproveitou melhor a energia disponível, proporcionando aos sistemas, maiores rendimentos de grãos. Para o balanço energético, repetiu-se, em parte, o desempenho da conversão energética dos sistemas de rotação de culturas, na qual os sistemas II e III superaram a monocultura trigo/soja (sistema I). Por incorporarem a prática de rotação de culturas em suas composições, devem ser preferidos, em substituição ao sistema I, monocultura trigo/soja.

ZENTNER et al. (1984, 1989) desenvolveram pesquisas com 12 sistemas de rotação de culturas para trigo, durante 12 e 18 anos, respectivamente, e não verificaram diferenças significativas quanto ao balanço energético entre um ou dois anos sem essa gramínea e a monocultura.

SANTOS et al. (2000), trabalhando com sistemas mistos, durante seis anos, sob plantio direto, observaram que os sistemas II (trigo/soja e aveia preta pastejada/milho - $99.325 \mathrm{~kg} \mathrm{MJ}^{-1}$ ) e III (trigo/soja, aveia preta + ervilhaca pastejadas/soja e aveia preta + ervilhaca pastejadas/milho - $91.008 \mathrm{~kg} \mathrm{MJ}^{-1}$ ) obtiveram maiores índices de balanço energético do que os sistemas I (trigo/soja, aveia preta pastejada/ soja e aveia preta pastejada/soja - $48.361 \mathrm{~kg} \mathrm{MJ}^{-1}$ ) e IV (trigo/soja, aveia branca/soja e aveia branca/soja - $53.911 \mathrm{~kg} \mathrm{MJ}^{-1}$ ). Constatou-se em SANTOS et al. (2001), durante nove anos, que os sistemas de rotação de culturas, na maioria das safras, foram energeticamente mais eficientes do que a monocultura trigo/soja ou pousio/soja.

\section{CONCLUSÕES}

1. O plantio direto foi o sistema de manejo de solo mais eficiente energeticamente, em relação aos demais sistemas de manejo de solo.

2. Os maiores índices de conversão energética e de balanço energético ocorreram nos sistemas II (trigo/soja e ervilhaca/milho ou sorgo) e III (trigo/soja, ervilhaca/milho ou sorgo e aveia branca/soja). 


\section{REFERÊNCIAS}

BORIN, M.; MENINI, C.; SARTORI, L. Effects of tillage systems on energy and carbon balance in north-eastern Italy. Soil \& Tillage Research, Amsterdan, v.40, n.3/4, p.209-226, 1997.

BUENO, O.C.; CAMPOS, A.T.; CAMPOS, A.T. Balanço de energia e contabilização da radiação global: simulação e comparativo. In: BUENO, O.C. Avances en ingeniería agrícola. Buenos Aires : Editorial Faculdad de Agronomía, 2000. p.477-482.

BURT, E.C.; REEVES, D. W.; RAPER, R. L. Energy utilization as affected by traffic in a conventional and conservation tillage system. Transactions of the Asae, St. Joseph, v. 37, n. 3, p. 759$762,1994$.

CAMPOS, A.T.; CAMPOS, A.T. Balanços energéticos agropecuários: uma importante ferramenta como indicativo de sustentabilidade de agrosistemas. Ciência Rural, Santa Maria, v.34, n.6, p.1977-1985, 2004.

COMITRE, V. A eficiência energética na atividade florestal. Informações Econômicas, São Paulo, v.25, n.10, p.61-67, 1995.

DE MORI, C. Mensuração do desempenho produtivo de unidades de produção agrícola considerando aspectos agroeconômicos e agroenergéticos. 1998. 65f. Dissertação (Mestrado em Engenharia de Produção) - Universidade Federal de Santa Catarina, Florianópolis, 1988.

EMBRAPA. Centro Nacional de Pesquisa de Suínos e Aves. Tabela de composição química e valores energéticos de alimentos para suínos e aves. 3.ed. Concórdia, 1991. 97p. (Documentos, 19)

FREITAS, E.A.G. de; DUFLOTH, J.H.; GREINER, L.C. Tabela de composição química-bromatológica e energética dos alimentos para animais ruminantes em Santa Catarina. Florianópolis: Epagri, 1994. 33p. (Documentos, 155)

HERNÁNZ, J.L.; GIRÓN, V.S.; CERISOLA, C. Long-term energy use and economic evaluation of three tillage systems for cereal and legume production in Central Spain. Soil \& Tillage Research, Amsterdan, v.35, n.4, p.183-198, 1995.

HETZ, E.J.; BARRIOS A.I. Reduccion del costo energetico de labranza/siembra utilizando sistemas conservacionistas en Chile. Agro-Ciencia, Chapingo, v.13, n.1, p.41-47, 1997.

HETZ, E.J.; MELO, L.A. Evaluacion energetica de un sistema de produccion de maiz y trigo com cero labranza: el caso de Chequen, Concepcion, Chile. Agro-Ciencia, Chapingo, v.13, n.2, p.181-187, 1997.

MARCHIORO, N.P.X. Balanço ecoenergético: uma metodologia de análise de sistemas agrícolas. In: TREINAMENTO EM ANÁLISE ECOENERGÉTICA DE SISTEMAS AGRÍCOLAS, 1., 1985, Curitiba, PR. Curitiba : Iapar, 1985. p.24-40.

MESQUITA, C.M.; ROESSING, A.C.; GAZZIERO, D.L.P. Consumo de energia e avaliação técnico-econômica de sistemas de produção de soja. In: SEMINÁRIO NACIONAL DE PESQUISA DE SOJA, 2., 1981. Brasília. Anais... Londrina: Embrapa Soja, 1982. v.1, p.525-538.
MONEGAT, C. Avaliação multidimensional do desempenho do manejo do solo no sistema do pequeno agricultor. 1998. 144f. Tese (Mestrado em Agrossistemas) - Centro de Ciências Agrárias, Universidade Federal de Santa Catarina, Florianópolis, 1998.

PELLIZZI, G. Use of energy and labour in Italian agriculture. Journal of Agricultural Engineering Research, London, v.52, n.1, p.111-119, 1992.

PIMENTEL, D. (Ed.). Handbook of energy utilization in agriculture. Boca Raton: CRC Press, 1980. 475p.

QUESADA, G.M.; BEBER, J.A.C. Energia e mão-de-obra. Ciência Hoje, Rio de Janeiro, v.11, n.62, p.21-26, 1990.

QUESADA, G.M.; BEBER, J.A.C.; SOUZA, S.P. de. Balanços energéticos agropecuários. Uma proposta metodológica para o Rio Grande do Sul. Ciência e Cultura, São Paulo, v.39, n.1, p.20-28, 1987.

REGO, P.Q. A sustentabilidade do plantio direto. In: ENCONTRO LATINO AMERICANO SOBRE PLANTIO DIRETO NA PEQUENA PROPRIEDADE, 1., 1993, Ponta Grossa. Anais... Ponta Grossa: SEAB; Iapar, 1993. p.89-100.

SANTOS, H.P.; REIS, E.M. Rotação de culturas em Guarapuava, PR. Brasil. XVI. Eficiência energética dos sistemas de rotações de culturas com trigo, em plantio direto. Pesquisa Agropecuária Brasileira, Brasília, v.30, n.2, p.215-222, fev. 1995.

SANTOS, H.P.; FONTANELI, R.S.; IGNACZAK, J.C.; ZOLDAN, S.M. Conversão e balanço energético de sistemas de produção de grãos com pastagens sob sistema plantio direto. Pesquisa Agropecuária Brasileira, Brasília, v.35, n.4, p.743-752, abr. 2000.

SANTOS, H.P.; LHAMBY, J.C.B.; IGNACZAK, J.C.; SCHNEIDER, G.A. Conversão energética e balanço energético de sistemas de sucessão e de rotação de culturas. Ciência Rural, Santa Maria, v.1, n.2, p.191-198, 2001.

SANTOS, H.P.; IGNACZAK, J.C.; LHAMBY, J.C.B.; CARMO, C. do. Conversão e balanço energético de sistemas de manejo de solo e de rotação de culturas. Pesquisa Agropecuária Gaúcha, Porto Alegre, v.9, n.1/2, p.113-120, 2003.

STATISTICAL ANALYSIS SYSTEMS INSTITUTE. SAS system for Microsoft Windows, version 8.2. Cary, 2003.

ZENTNER, R.P.; STUMBORG, M.A.; CAMPBELL, C.A. Effect of crop rotation and fertilization on energy balance in typical production systems on the Canadian prairies. Agriculture, Ecosystems, and Environment, Amsterdam, v.25, n.2/3, p.217232, 1989.

ZENTNER, R.P.; CAMPBELL, D.W.; CAMPBELL, C.A.; REID, D.W. Energy consideration of crop rotation in southwestern Saskatchewan. Canadian Agricultural Engineering, Ottawa, v.26, n.1, p.25-29, 1984.

ZENTNER, R.P.; TESSIER, S.; PERU, M.; DYCK, F.B.; CAMPBELL, C.A. Economics of tillage systems for spring wheat production in southwestern Saskatchewan. Soil \& Tillage Research, Amsterdan, v.21, n.3/4, p. 225-242, 1991. 